\title{
Note from the Editor,
}

The commitment of the journal Transinformação is to disseminate research and reflections in the field of Information Science. Every year, the journal acquires singularities that go beyond national territorial boundaries by adding valuable international contributions to each issue.

Unequivocally, the dynamics itself is a constant step towards the dissemination of scientific activities in a broad and unrestricted way in an endeavor to further the process of knowledge development.

And it is precisely in this process that Transinformação strives to offer readers a set of reflections from the field of Information Science and related areas with the support of expert national and international authors.

The members of the editorial board at Transinformação reaffirm our ethical commitment to the scientific quality and regularity of issues in 2017, wishing that the published articles be of great value.

We wish you all a great read!

Rogério Eduardo Rodrigues Bazi

Editor in chief 